\title{
SIMULASI PENGARUH FRICTION, SPEED, MATERIAL, DAN TEMPERATURE TERHADAP DAMAGE PADA BLOCK PRE FORMING DENGAN METODE TAGUCHI
}

\author{
Dicky Adi Tyagita ${ }^{1)}$, Asroni ${ }^{2}$ \\ Jurusan Teknik Mesin Universitas Muhammadiyah Metro \\ J1. Ki Hjar Dewantara No. 116 Kota Metro \\ E-mail : dicky_doank@yahoo.co.id ${ }^{1)}$
}

\begin{abstract}
ABSTRAK
Pada proses pembentukan logam damage dapat disebabkan oleh beberapa faktor yaitu beban yang bekerja pada benda kerja, temperatur pemanasan awal, dan temperatur yang disebankan gesekan antara die dan material yang akan di lakukan pre forming. Proses metal forming bisa dilakukan dengan 2 cara yaitu pengerjaan panas (hot working) dan pengerjaan dingin (cold working). Pada proses pengerjaan panas dan pengerjaan dingin logam mengalami deformasi plastis dan perubahan bentuk. Pada pengerjaan panas, gaya deformasi yang diperlukan adalah lebih rendah dan perubahan sifat mekanik juga tidak siknifikan. Pada pengerjaan dingin, diperlukan gaya yang lebih besar, akan tetapi kekuatan logam tersebut akan meningkat secara signifikan. Tren penggunaan simulasi semakin meningkat dikarenakan mampu memprediksi dan menggambarkan mekanisme proses serta mendapatkan optimasi proses pre forming. Studi yang dilakukan menggunakan simulasi 3 dimensi (3D) untuk memprediksi pengaruh variasi friction, speed, material, dan temperature terhadap damage pada block pre forming. Dari hasil simulasi menunjukkan nilai damage terbesar terlihat pada spesimen nomor 9 dengan nilai damage tertinggi sebesar 0,0302 pada variasi friction sebesar 0,2; speed punch 2 inc/s, material al 2xxx, dan temperature $122{ }^{\circ} \mathrm{F}$. Nilai damage terendah terlihat pada spesimen nomor 6 dengan nilai damage tertinggi sebesar 0,0101 pada variasi friction sebesar 0,12; speed punch $2 \mathrm{inc} / \mathrm{s}$, material al 1xxx, dan temperature $122{ }^{\circ} \mathrm{F}$. Nilai load prediction terbesar terlihat pada grafik 1 dengan nilai $1470 \mathrm{klbf}$. Nilai load prediction terkecil terlihat pada grafik 6 dengan nilai $155 \mathrm{klbf}$.
\end{abstract}

Kata kunci: friction, speed, material, temperature, damage

\section{Pendahuluan}

Metal forming adalah proses pembentukan logam secara plastis dengan mempergunakan gaya tekan untuk mengubah bentuk atau ukuran dari logam yang dikerjakan. Proses metal forming bisa dilakukan dengan 2 cara yaitu pengerjaan panas (hot working) dan pengerjaan dingin (cold working). Metal forming bisa dilakukan dengan manual atau dengan mesin hidrolis karena bisa membuat tekanan dengan tenaga yang besar. Tetapi jika menggunakan tenaga pneumatik, tenaga yang dihasilkan lebih kecil. ${ }^{2}$

Dua jenis pengerjaan mekanik dimana logam mengalami deformasi plastis dan perubahan bentuk adalah pengerjaan panas dan pengerjaan dingin. Pada pengerjaan panas, gaya deformasi yang diperlukan adalah lebih rendah dan perubahan sifat mekanik juga tidak siknifikan. Pada pengerjaan dingin, diperlukan gaya yang lebih besar, akan tetapi kekuatan logam tersebut akan meningkat secara signifikan. ${ }^{1}$

Suhu rekristalisasi logam menentukan batas antara pengerjaan panas dan dingin. Pengerjaan panas logam dilakukan di atas suhu rekristalisasi atau di atas daerah pengerasan kerja. Pengerjaan dingin dilakukan di bawah suhu rekristalisasi dan kadang-kadang berlangsung pada suhu ruang. Suhu rekristalisasi baja berkisar antara $500{ }^{\circ} \mathrm{C}$ dan $700^{\circ} \mathrm{C}$.

\section{Metodologi}

\section{Diagram alir Penelitian}

Untuk mengetahui pengaruh variasi friction, speed, material, dan temperature terhadap damage pada block pre forming dengan simulasi komputer. Dilakukan dengan memodelkan proses pre forming dengan memanfaatkan software berbasis metode elemen hingga. Langkah-langkah yang dilakukan dijelaskan oleh diagram alir 
pada gambar 1 .

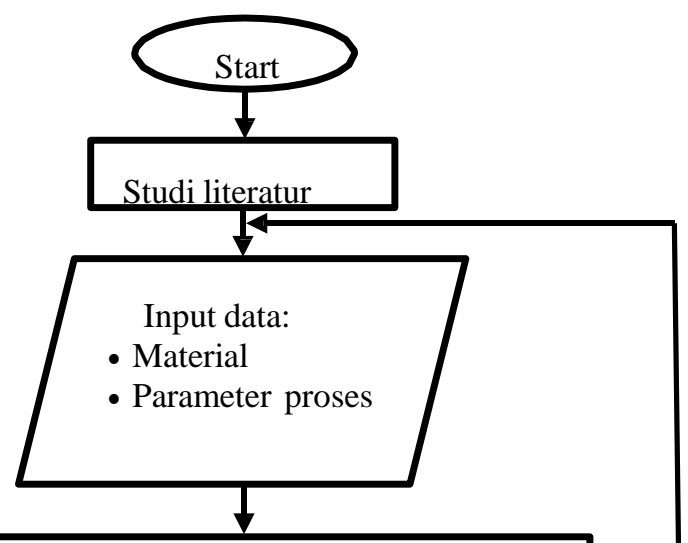

Pemodelan benda kerja dengan parameter proses Variabelbebas: Friction $(0.1,0.12$, dan 0.2) Kecepatan (0.5 in/s, 1 in/s, 2 in/s) Temperatur $\left(80.6{ }^{\circ} \mathrm{F}, 122{ }^{\circ} \mathrm{F}\right.$, dan $\left.158{ }^{\circ} \mathrm{F}\right)$ Material: (Aluminiumseri 1xxx, 2xxx, dan $3 \times x x)$

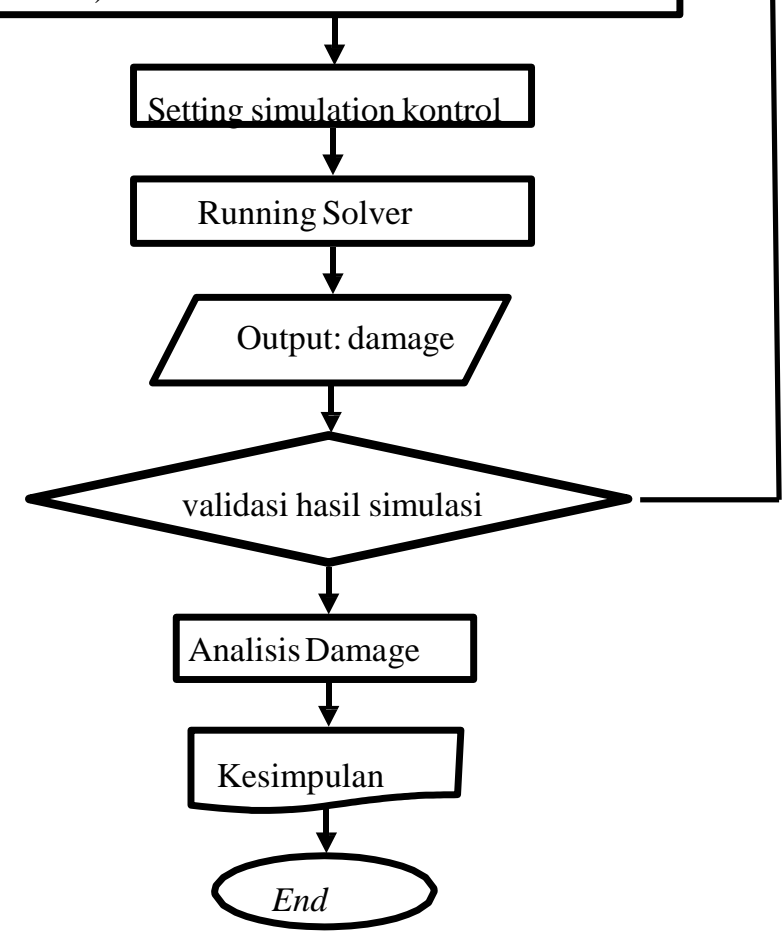

Gambar 1 . Diagram Alir Penelitian

\section{Variabel}

Variabel yang digunakan dalam penelitian ini adalah:

1. Variabel bebas :

- Friction (0.1, 0.12, dan 0.2);

- Speed (0.5 in/s, 1 in/s, 2 in/s);

- Temperature $\left(80.6{ }^{\circ} \mathrm{F}\right.$, ${ }^{\circ} \mathrm{F}$, dan158 $\left.{ }^{\circ} \mathrm{F}\right)$;
- Materials: (Aluminium seri 1xxx, 2xxx, dan 3xxx).

2. Variabel terikat:

Variabel terikat dalam penelitian ini adalah

- Damage

3. Variabel terkontrol

Variabel terkontrol dalam penelitian ini adalah :

- Constant die Displacement : 0.13

- Dies : Rigid

\section{Spesifikasi Material Benda Kerja dan} Punch

- Spesifikasi material benda kerja

Bahan yang digunakan dalam penelitian ini adalah top die dan bottom die rigid serta block (benda kerja) yang berbahan aluminium seri $1 \mathrm{xxx}$, 2xxx, dan 3xxx

- Spesifikasi material die Material die $=$ Rigid

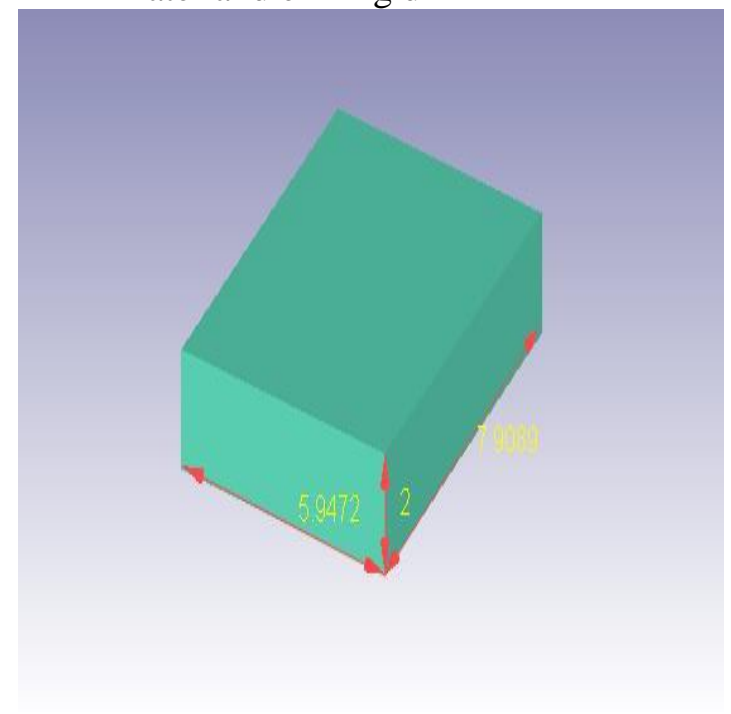

Gambar 2. Die

\section{Pemodelan Pre Forming}

Metal forming dimodelkan secara 3 dimensi dengan memberikan variasi friction $(0.1,0.12$, dan 0.2); kecepatan $(0.5 \mathrm{in} / \mathrm{s}, 1 \mathrm{in} / \mathrm{s}$,

$2 \mathrm{in} / \mathrm{s})$; temperature $\left(80.6{ }^{\circ} \mathrm{F}, 122{ }^{\circ} \mathrm{F}\right.$, dan $158{ }^{\circ} \mathrm{F}$ ); material: (aluminium seri $1 \mathrm{xxx}, 2 \mathrm{xxx}$, dan 3xxx). 
Dicky Adi Tyagita, Asroni

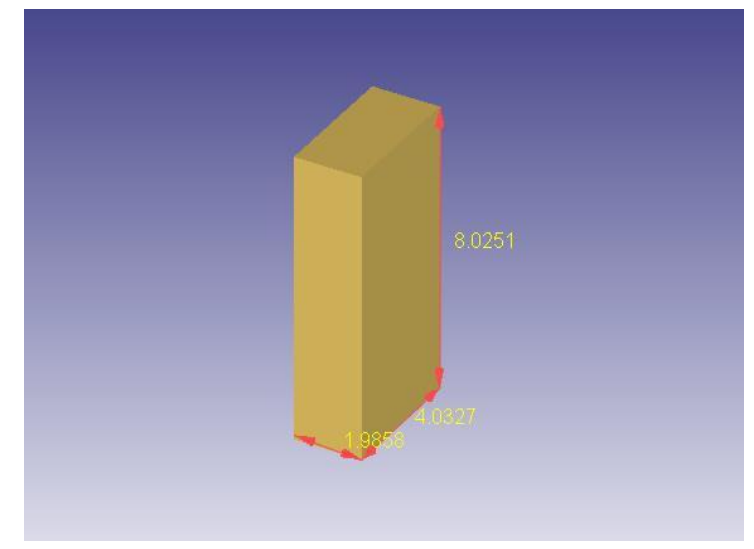

Gambar 3. Dimensi benda Kerja

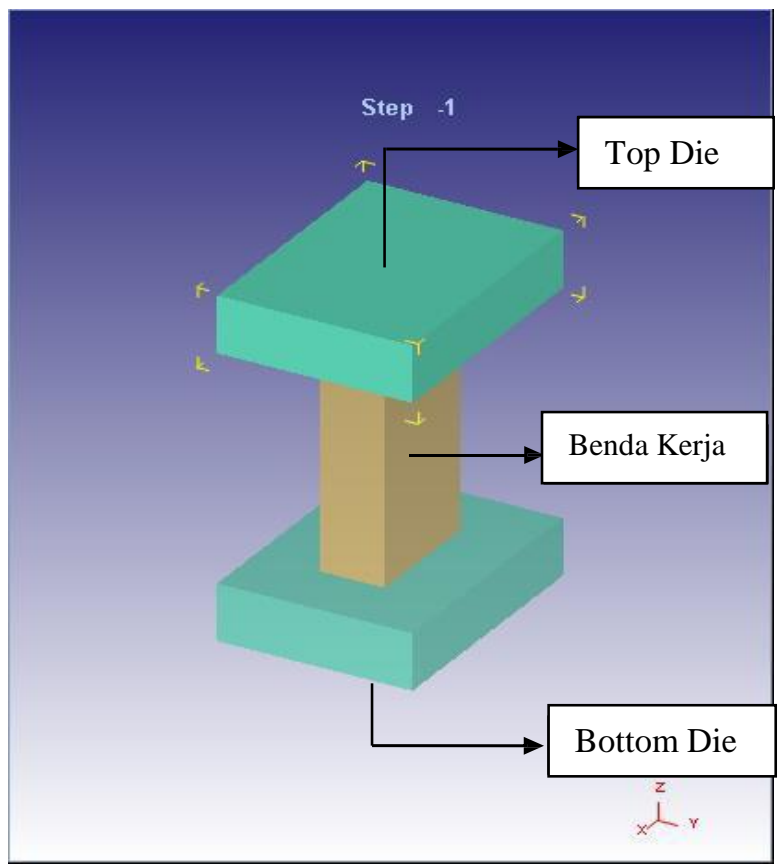

Gambar 4. Pemodelan benda kerja

Tabel 1. Pemodelan variasi pada pre forming

\begin{tabular}{|l|l|l|l|l|}
\hline Spesimen & Friction & $\begin{array}{l}\text { Speed } \\
\text { Punch }\end{array}$ & $\begin{array}{l}\text { Material } \\
\text { ture }\end{array}$ \\
\hline 1 & 0,1 & $0,5 \mathrm{inc} / \mathrm{s}$ & $\mathrm{Al} 1 \mathrm{xxx}$ & $80,6^{\circ} \mathrm{F}$ \\
\hline 2 & 0,1 & $1 \mathrm{inc} / \mathrm{s}$ & $\mathrm{Al} 2 \mathrm{xxx}$ & $122^{\circ} \mathrm{F}$ \\
\hline 3 & 0,1 & $2 \mathrm{inc} / \mathrm{s}$ & $\mathrm{Al} 3 \mathrm{xxx}$ & $158^{\circ} \mathrm{F}$ \\
\hline 4 & 0,12 & $0,5 \mathrm{inc} / \mathrm{s}$ & $\mathrm{Al} 2 \mathrm{xxx}$ & $158^{\circ} \mathrm{F}$ \\
\hline 5 & 0,12 & $1 \mathrm{inc} / \mathrm{s}$ & $\mathrm{Al} 3 \mathrm{xxx}$ & $80,6^{\circ} \mathrm{F}$ \\
\hline 6 & 0,12 & $2 \mathrm{inc} / \mathrm{s}$ & $\mathrm{Al} 1 \mathrm{xxx}$ & $122^{\circ} \mathrm{F}$ \\
\hline 7 & 0,2 & $0,5 \mathrm{inc} / \mathrm{s}$ & $\mathrm{Al} 3 \mathrm{xxx}$ & $122^{\circ} \mathrm{F}$ \\
\hline 8 & 0,2 & $1 \mathrm{inc} / \mathrm{s}$ & $\mathrm{Al} 1 \mathrm{xxx}$ & $158^{\circ} \mathrm{F}$ \\
\hline 9 & 0,2 & $2 \mathrm{inc} / \mathrm{s}$ & $\mathrm{Al} 2 \mathrm{xxx}$ & $80,6^{\circ} \mathrm{F}$ \\
\hline
\end{tabular}

\section{Hasil dan Pembahasan}

Dari hasil simulasi yang telah dilakukan dapat dilihat gambar dan grafik pengaruh friction, speed, material, dan temperature terhadap damage pada block pre forming pada Gambar 5 dan 6.

Tabel 2. Nilai Damage

\begin{tabular}{|l|l|}
\hline Spesimen & Damage tertinggi \\
\hline 1 & 0,0193 \\
\hline 2 & 0,0166 \\
\hline 3 & 0,0163 \\
\hline 4 & 0,0195 \\
\hline 5 & 0,0191 \\
\hline 6 & 0,0101 \\
\hline 7 & 0,0186 \\
\hline 8 & 0,0176 \\
\hline 9 & 0,0302 \\
\hline
\end{tabular}
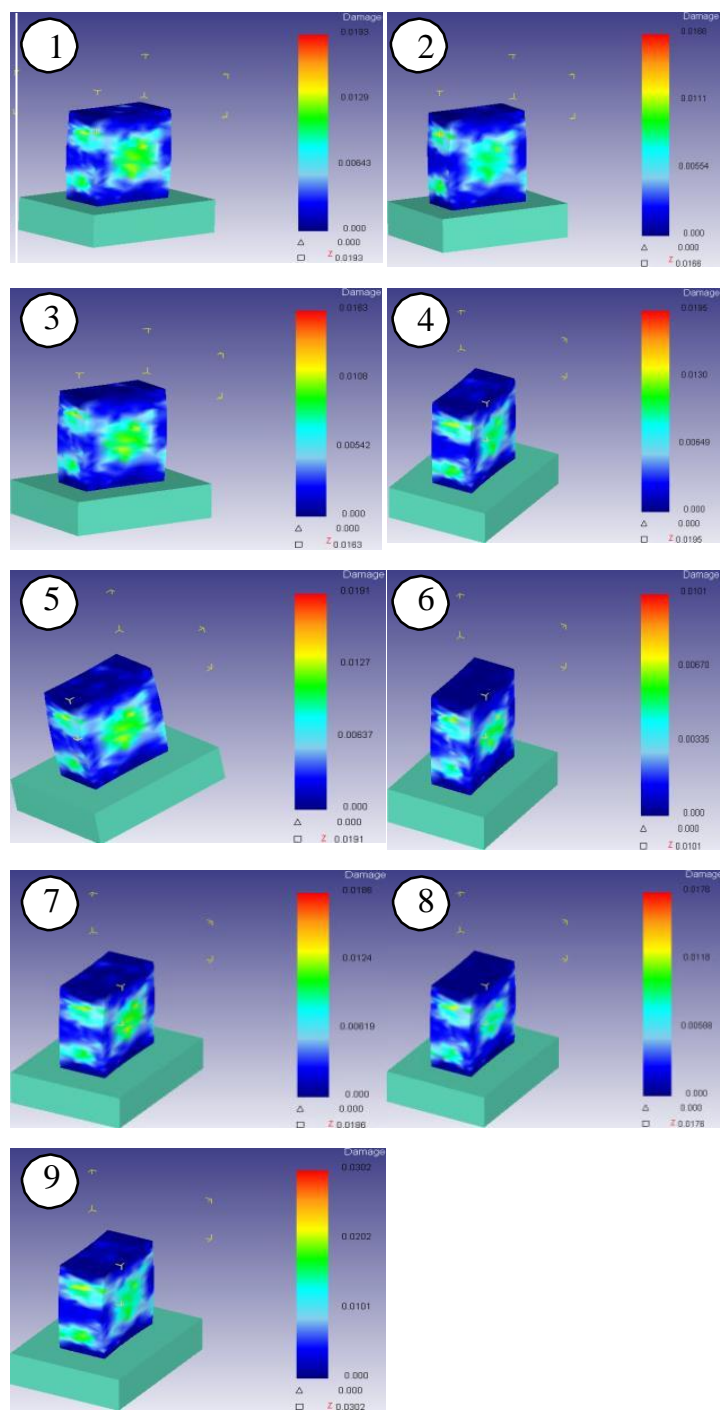

Gambar 5. Distribusi damage pada block pre forming 
Dicky Adi Tyagita, Asroni

Dari gambar 5 dapat diketahui bahwa nilai damage terbesar terlihat pada spesimen nomor 9 dengan nilai damage tertinggi sebesar 0,0302 . Hal ini disebabkan pada spesimen nomor 9 ini, proses pembentukan logam dilakukan pada suhu kamar $\left(80,6{ }^{\circ} \mathrm{F}\right)$ sehingga tidak ada proses pemanasan logam yang terjadi sebelum proses pembentukan.

Selama proses pembentukan terjadi strain hardening, logam akan menjadi lebih keras yang diikuti dengan penurunan keuletan sehingga deformasi yang terjadi menjadi terbatas meskipun nilai friction dan speed punch sudah paling tinggi.

Nilai damage terendah terlihat pada spesimen nomr $6 \quad$ dengan nilai

damage tertinggi sebesar 0,0101. Hal ini disebabkan pada spesimen nomor 6 ini, proses pembentukan logam dilakukan pada suhu $122{ }^{\circ} \mathrm{F}$ sehingga terjadi pelunakan sebelum dan selama proses pembentukan logam secara terus menerus hal ini juga ditunjang oleh nilai friction sebesar 0,12 dan speed punch sebesar 2 inc/s sehingga semakin meningkatkan temperature proses pembentukan logam sehingga deformasi yang terjadi cukup besar.
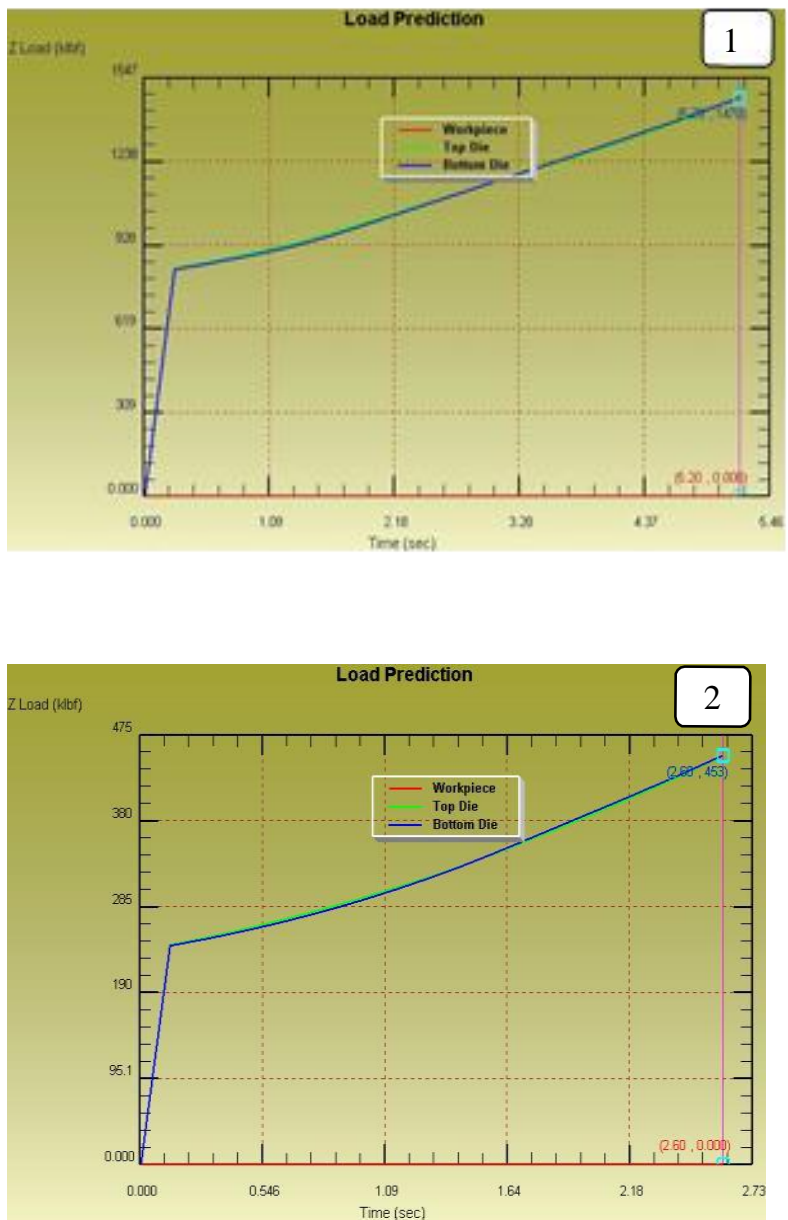
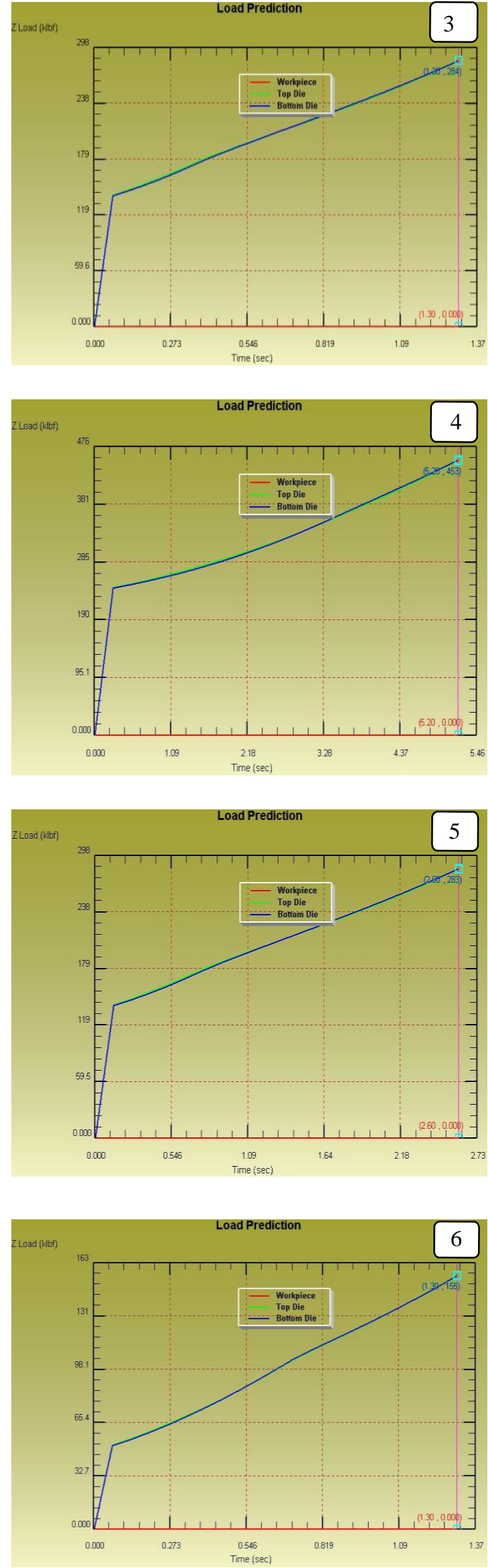

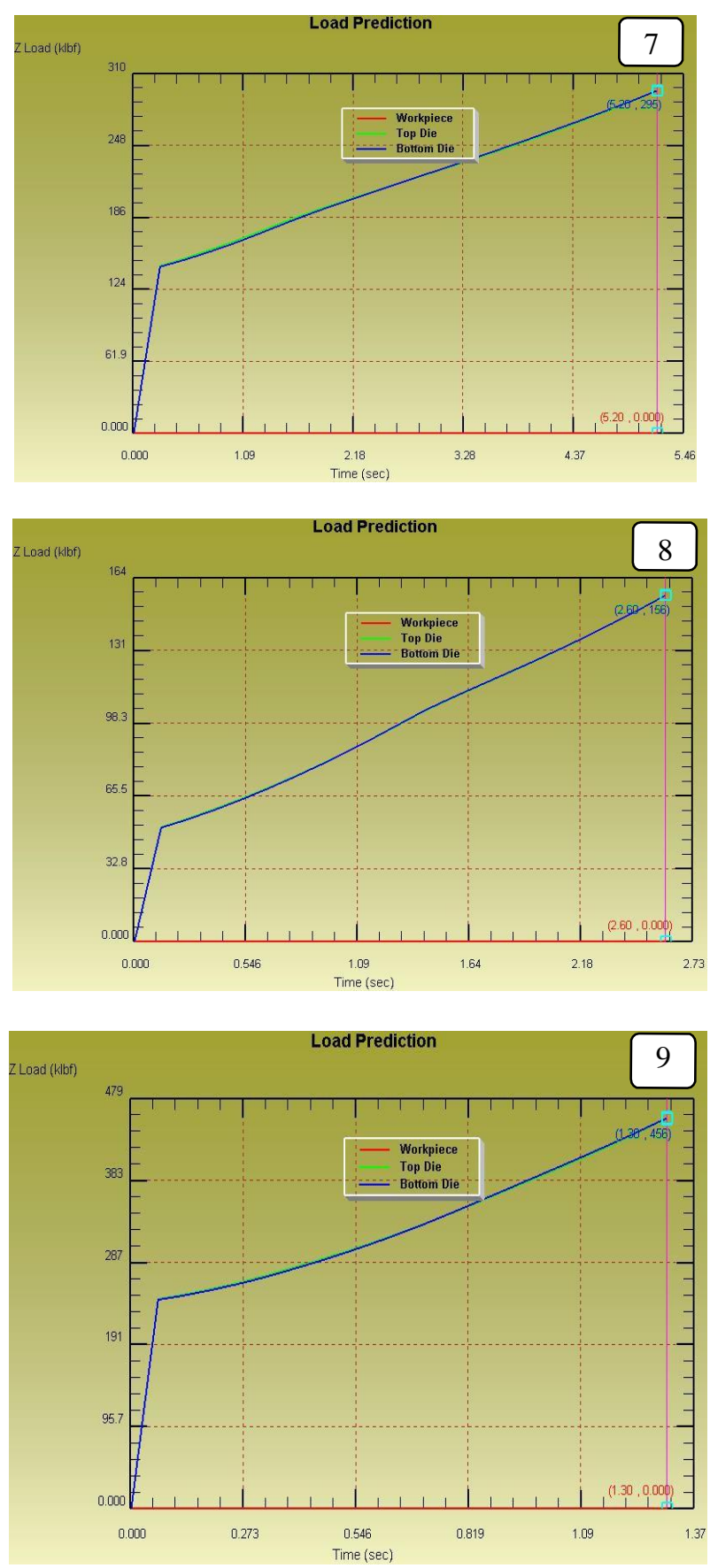

Gambar 6. Grafik Load Prediction

Dari gambar 6 dapat diketahui bahwa nilai load prediction terbesar terlihat pada grafik 1 dengan nilai 1470 klbf. Nilai load prediction terkecil terlihat pada grafik 6 dengan nilai 155 klbf. Hal ini berarti semakin kecil nilai variasi friction, speed punch, material, dan temperature maka semakin besar pembebanan yang terjadi gaya yang dibutuhkan semakin besar. Sebaliknya semakin besar nilai variasi friction, speed punch, material, dan temperature maka semakin kecil pembebanan yang terjadi gaya yang dibutuhkan semakin kecil.

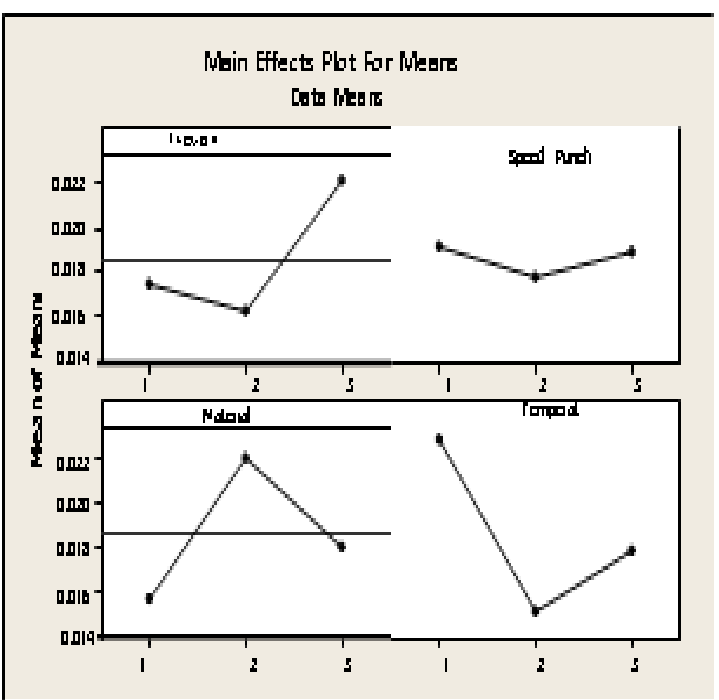

Gambar 7: Main Effects Plot for Means

Dari gambar 7 dapat diketahui bahwa:

\section{Friction}

Nilai damage terbesar terletak pada variasi friction dengan nilai 0,2 dan nilai damage terkecil terletak pada variasi friction dengan nilai 0,12 .

\section{Speed Punch}

Nilai damage terbesar terletak pada variasi speed punch dengan nilai 0,5 inc/s dan nilai damage terkecil terletak pada variasi speed punch dengan nilai 0,1 inc/s.

\section{Material}

Nilai damage terbesar terletak pada variasi material dengan jenis $\mathrm{Al} 2 \mathrm{xxx}$ dan nilai damage terkecil terletak pada variasi material dengan jenis Al 1xxx.

4. Temperature

Nilai damage terbesar terletak pada variasi temperature dengan nilai $80,6{ }^{\circ} \mathrm{F}$ dan nilai damage terkecil terletak pada variasi temperature dengan nilai $122^{\circ} \mathrm{F}$.

Semakin tinggi temperature, friction, dan speed punch kekuatan dan kekerasan akan menurun sehingga dapat terjadi proses deformasi plastis. Deformasi disebabkan adanya beban tekan yang akan mengubah bentuk awal benda kerja meskipun bebannya dihilangkan. Hasil dari simulasi juga mendukung fenomena tersebut dimana dengan semakin meningkatnya temperature, friction, dan speed punch maka deformasi plastis yang terjadi semakin besar dan menurunkan nilai damage. 


\section{Dicky Adi Tyagita, Asroni}

\section{Kesimpulan}

Dari analisa hasil dan pembahasan, maka dapat diambil beberapa kesimpulan, sebagai berikut :

1. Nilai damage terbesar terlihat pada spesimen nomor 9 dengan nilai damage tertinggi sebesar 0,0302 pada variasi friction sebesar 0,$2 ;$ speed punch 2 inchi/s, material $\mathrm{Al} \quad 2 \mathrm{xxx}, \quad$ dan temperature $122{ }^{\circ} \mathrm{F}$.

2. Nilai damage terendah terlihat pada spesimen nomor 6 dengan nilai damage tertinggi sebesar 0,0101 pada variasi friction sebesar 0,12 ; speed punch $2 \mathrm{inc} / \mathrm{s}$, material $\mathrm{Al} 1 \mathrm{xxx}$, dan temperature $122^{\circ} \mathrm{F}$.

3. Nilai load prediction terbesar terlihat pada grafik 1 dengan nilai $1470 \mathrm{klbf}$.

4. Nilai load prediction terkecil terlihat pada grafik 6 dengan nilai $155 \mathrm{klbf}$.

5. Dengan simulasi 3D, dapat dikembangkan optimasi parameter pre forming untuk mengurangi damage pada benda kerja.

\section{Daftar Pustaka}

1. Saptono, Rahmat. 2005. Analisis Proses Pembentukan Logam. Jakarta: Universitas Indonesia.

2. Moaveni, Saeed. 1999. Finite Element Analysis Theory and Application with ANSYS. New Jersey : Prentice Hall.

3. Nakazawa, Tamura dan Yoshida. 2005. Develoment Of Crash-Box For Passenger Car With High Capability For Energy Absorption. Jepang.

4. Nentchev, A. 2002. Numerical Analysis and Simulation in Microelectronics by Vector Finite Elements. USA.

5. Robert D. Cook, David S. Malkus dan Michael E. Plesha. 1989. Concepts and Applications of Finite Element Analysis. Canada: Wiley.

6. Segerlind, Larry J. 1984. Applied Finite Element Analysis. Canada : John Wiley \& Sons

7. Velmurugan and Muralikannan. (2009). Energy Absorption Characteristics of Annealed Steel Tubes of Various Cross Sections in Static and Dynamic Loading. India.

8. Witteman. 1999. Improved Vehicle Crashworthiness Design by Control of the Energy Absorption for Different Collision Situations. Belanda.
9. Yanjie, Liu. 2008. Computer Simulations and Experimental Study on Crash Box of Automobile in Low Speed Collision. Chin 